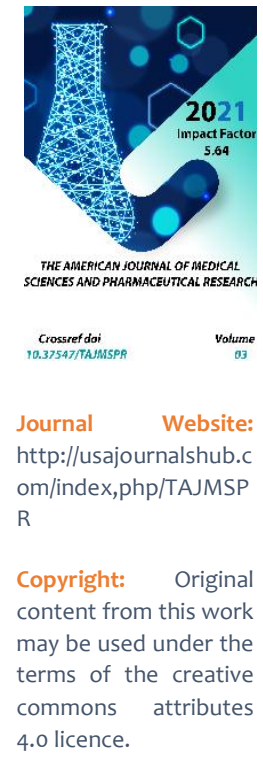

\title{
Regional Causes Of Iron Deficiency Anemia, Pathogenesis And Use Of Antianemic Drugs
}

\section{Sulaymanova Gulnoza Tulkindzanovna}

MD, Assistant Of Department Of Faculty And Hospital Therapy, Bukhara State Medical Institute, Uzbekistan

\section{Amonov Muhammad Komilovich}

Md, Assistant Of Department Of Faculty And Hospital Therapy, Bukhara State Medical Institute, Uzbekistan

\section{ABSTRACT}

The article describes the pathogenesis of occurring of iron deficiency anemia. The study was conducted in Bukhara. According to him, in each critical period, specific etiological factors predominate, and it is the elimination of these factors in the first place that increases the effectiveness of treatment. The main factors of iron defiency anemia are alimentary insufficiency of in girls of childbearing age is the onset of menstruation, and in women of childbearing age, improper use of intrauterine devices, frequent abortions, metroragias for various reasons, alimentary insufficiency and incomplete acceptance of the previous course of ferrotherapy.

\section{KEYWORDS}

Iron deficiency anemia, fertile age, metroragia, ferrotherapy, alimentary insufficiency.

\section{INTRODUCTION}

Iron deficiency anemia (IDA) is a complex of clinical and hematological symptoms characterized by impaired hemoglobin synthesis due to iron deficiency in blood plasma and bone marrow, resulting in changes in the trophic development of organs and tissues.

IDA has been an important medical problem for many years due to its prevalence. 
According to the World Health Organization (WHO), 1,987,300,000 people worldwide suffer from anemia, of which $80-90 \%$, or $1,788,600,000$ people, suffer from IDA. In developed countries, this figure is lower than in developing countries. In Europe and North America, $7.5-11 \%$ of women of childbearing age suffer from IDA. This is due to a poor diet, high consumption of meat products and low number of pregnancies. $[1,7]$

Iron is a microelement involved in many metabolic processes in the body, in particular, necessary for the normal functioning of the red blood cells. The body receives most of the iron by recirculation from apoptotic erythrocytes. In addition, iron is absorbed by food and absorbed by enterocytes in the upper gastrointestinal tract (GIT). This part plays an important role in meeting the body's need for iron, because the origin of anemia is often associated with this part. Examination with Dxylose and radioactive iron revealed the absorption of iron in the proximal part of the OIT, in the complex "duodenum + small intestine".[1, 5, 7]

Iron in food in the gem state (in animal products - meat, fish, which makes up $40 \%$ of all iron and is better assimilated) and in the nongem state (in fruits, vegetables, grains, nuts and plant products) is $60 \%$ of all iron and is relatively poorly absorbed) in the duodenum. Here, trivalent $\mathrm{Fe}_{3}+$ is converted to $\mathrm{Fe}_{2}+$, which is reversed by seruloplasmin, which acts as a ferroxidase. In the basolateral part of the duodenal-intestinal enterocytes, cefestin and seruloplasmin convert $\mathrm{Fe}_{2}+$ into $\mathrm{Fe}_{3}+$. This process ensures the conversion of iron to transferrin without the release of toxic substances. The conversion of iron from food to biometals involves cytosol, divalent metal transporter, hepsidine, ferroportin, hefestin. In the body, iron is stored in the cell, outside the cell and in reserve.
Cellular iron is stored in the following:

1) Primarily in the composition of hemoproteins (hemoglobin, mioglobin, cytochrome, catalase and peroxidase)

2) In the composition of iron-containing enzymes that are nongem (succinate dehydrogenase, acetyl-coenzyme-Adehydranase, NADN-cytochrome, Creductase, etc.)

\section{MATERIALS AND METHODS}

Extracellular iron is present in the proteins transferrin and lactoferrin, which transport iron ions. Transferrin is a plasma protein that is included in b-globulins. In humans, it is synthesized in the liver. Lactoferrin is a protein belonging to the transferrin group, which carries trivalent iron ions.

Iron reserves are ferritin and hemosiderin proteins, which accumulate in the liver, spleen and muscles. It is activated in case of cellular iron deficiency.

\section{RESULTS}

80 and $90 \mathrm{mg}$ of labile iron nuclei are present. They can leave the blood plasma into the interstitial space, from there into the intercellular space, adhere to the cell membrane and return to the plasma. $[2,3,8]$

According to Jacobs Worwood (1974), a healthy person weighing $70 \mathrm{~kg}$ contains $4.5 \mathrm{~g}$ of iron, which is involved in important metabolic processes in the body. Iron from food makes up $20 \%$ of the total iron in the body. The rest consists of iron in iron and reserve ferritin and hemosiderin in enzymes such as hemoglobin, carrier transferrin, lactoferrin. The most ironcontaining products (per $100 \mathrm{~g}$ ) - beef liver - 9.8 $\mathrm{g}$, buckwheat $-8.0 \mathrm{~g}$, beef tongue $-5.0 \mathrm{~g}$, beans - $12.4 \mathrm{~g}$, peas - $9.4 \mathrm{~g}$. . There must also be some conditions for the absorption of iron from food. Succinic acid, ascorbic acid, citric acid, fructose, methionine and cysteine in food 
accelerate the absorption of iron, while phosphates, oxalate, calcium preservatives inhibit its absorption. The amount of iron absorbed by food is limited.

The body independently regulates the transfer of iron from the intestinal mucosa to the blood. When the amount of iron in the blood decreases, the iron in the mucous membrane passes into the blood. In the opposite case, the iron stored in the mucous membrane is combined with the end of the villi and passed into the feces and excreted from the body. In a healthy diet, if a man receives $18 \mathrm{mg}$ of iron per day, he absorbs 1-1.5 mg, and if a woman receives 12-15 $\mathrm{mg}$, she absorbs 1-1.3 $\mathrm{mg}$.

The maximum amount of absorbed iron does not exceed 2-2.5 mg. To this is added $21 \mathrm{mg}$ of iron in decomposed erythrocytes, $11 \mathrm{mg}$ of iron in the bone marrow, $1 \mathrm{mg}$ of depot. The total amount per day is $35 \mathrm{mg}$. Iron consumption: hemoglobin synthesis (17-40 mg), physiological losses (1 mg with feces, urine, sweat, skin epithelium). If there are no imbalances in the intake and consumption of iron in the body, the amount of iron in the body fully covers the amount consumed.

The reasons for IDA are:

1. Pathological blood loss

2. Disorders of iron absorption

3. Increased demand for iron

4. Alimentary deficiency

5. Lack of iron reserves in the environment

6. Disorders of iron transport.

Iron is often lost from the body due to blood loss. Pathological blood loss in women is mainly due to metroragia and hypermenorrhea. In a healthy woman, the menstrual cycle lasts 26-29 days, of which 3-5 days and the volume of blood lost does not exceed $90 \mathrm{ml}$. In this case, the body loses 1.5-1.7 $\mathrm{mg}$ of iron per day. If the menstrual period is long and heavy with bleeding (100-500 ml), then the amount of iron lost exceeds $3 \mathrm{mg}$ per day and can not be replaced by iron from food. Daily deficit is small (0.5-1 mg) $15-20 \mathrm{mg}$ per month, $189-240 \mathrm{mg}$ per year, $1.8-2.4 \mathrm{~g}$ in 10 years. Blood loss in women of reproductive age lasts an average of 40 years. At the age of $42-$ 45 years, a woman has a clear iron deficiency, although there are no health problems. Up to $500 \mathrm{ml}$ of blood is lost during physiological childbirth. As a result of these losses and losses during lactation, iron reserves are replenished only after 3 years of rational nutrition. Blood loss in men and women of childbearing age is mainly due to diseases of the gastrointestinal tract. Bleeding from duodenal ulcers $35-40 \%$, gastric ulcers - 15-20\%, erosive-hemorrhagic gastritis and esophagitis $15-20 \%$, bleeding due to acute and chronic diseases of the colon $20 \%$. $[4,9,11]$

In diseases of the duodenum and proximal part of the small intestine, even if the body receives enough iron, its absorption is impaired. If the need for iron in both boys and girls during adolescence increases due to the acceleration of metabolism, the amount of iron in the diet can not meet this need. The need for iron increases during pregnancy and lactation. . This is why iron deficiency anemia occurs. According to the WHO, pregnant and lactating women have $100 \%$ iron deficiency (hemoglobin is normal and there are signs of anemia due to a decrease in iron), of which $21-80 \%$ have IDA. Iron is important for the body, even in small amounts, for some reason, starvation, lack of iron-rich foods in the diet leads to depletion of iron reserves in the body. Environmental problems reduce iron content in the environment, soil, and water. This, in turn, 
leads to a lack of iron in plant and animal products. Therefore, even with a rational diet, the body does not get enough iron. It is known that iron is transported from the intestine by special enzymes transferrin and lactoferrin. Congenital deficiency of this enzyme leads to impaired absorption of iron.

Although factors such as gastrointestinal bleeding and frequent births leading to the above causes have been reduced to a minimum in the region, IDAs remain relevant.

The inspections conducted in Karakul and Alat districts of Bukhara region showed the following order of factors causing IDA. In the first place there are metroragias, often due to improper use of intrauterine devices to prevent pregnancy, IDA occurred after acute and chronic bleeding. In the second place, the nutritional factor plays a leading role. Regular consumption of tea and dairy products, which prevent the absorption of iron in the body, also causes the disease. The decision of the state to supplement flour and flour products with iron, as well as educational and cultural work aimed at promoting a healthy diet among the population did not reduce this factor. In third and fourth place are the short interval between births and frequent abortions. Although the number of children in the family is currently planned and the interval between births is more than 3 years, during this period there are more than 2 abortions due to gender planning and other reasons. $[3,9,10]$

Women of childbearing age highlight some of the above problems, despite the fact that some mistakes in family planning are actively explained by gynecologists and UASh doctors. The next places include helminthiasis and other causes. The prevalence of helminthiasis and various intestinal infections among children in our region creates the basis for the development of IDA. trichocephaly, $66.2 \%$ toxarosis was detected. These helminths adhere to the intestinal wall, leading to both blood loss and impaired iron absorption.

In the treatment of IDA should be identified the underlying disease (ulcer, carcinoma of the colon, kidney disease, etc.). Treatment with iron salts should be started after treatment of the underlying disease or after anemia is diagnosed as an independent disease.

Iron salts should be administered orally as much as possible. They differ in the degree of absorption, side effects and cost. In the treatment of IDA for an adult, the daily dose is 100-200 mg. Approximate amount of iron in various salts: iron fumarate $200 \mathrm{mg}(65 \mathrm{mg}$ iron), iron gluconate $300 \mathrm{mg}$ (35 mg iron), iron succinate $100 \mathrm{mg}$ (35 mg iron)), iron sulfate $300 \mathrm{mg}$ ( $60 \mathrm{mg}$ ), dry iron sulfate $200 \mathrm{mg}$ ( $65 \mathrm{mg}$ iron). Trivalent compounds of iron are less toxic than divalent, but iron is difficult to assimilate. A complex containing trivalent ironcarbohydrates, such as polymaltose iron complex, has good bioavailability and low toxicity (maltofer). Its effectiveness is equivalent to that of an iron sulphate preservative. Combined drugs are also easy to assimilate (gino-tardiferon - ferrous sulfate, mucoprotease, ascorbic acid, folic acid; Unicap $M$ - ferrous sulfate, ascorbic acid, riboflavin, nicotinamide, pyridoxine, calcium pantothenate; Actiferrin - ferrous sulfate, folic acid). An increase in reticulocyte count by 8 to 10 days of treatment and an increase in hemoglobin to $20 \mathrm{~g} \mathrm{/} \mathrm{I} \mathrm{after} 3$ weeks is considered an adequate response. Iron supplements are administered parenterally in cases of impaired iron absorption, inability to tolerate oral administration. However, its effect on erythropoiesis is small. After the hemoglobin level rises to normal, ferrotherapy should be continued at a maintenance dose for 3-6 months. $[6,9]$

\section{CONCLUSION}


It can be seen that women and children suffer the most from IDA. Today, iatrogenic metroragias, alimentary factors, and incomplete treatment are important causes of IDA. It is known that IDA is not a chronic disease, but the population suffers from it for many years. This is due to incomplete treatment and incomplete prevention or control.

\section{REFERENCES}

1. A multicentre comparative study on the efficacy of intravenous ferric carboxymaltose and iron sucrose for correcting preoperative anaemia in patients undergoing major elective surgery / E. Bisbe, J.A. Garcia-Erce, A.I. Diez-Lobo // British Journal of Anaesthesia. - 2011. - 107(3). - Pp. 477478.

2. Abdurakhmanov D.T. Iron deficiency anemia in diseases of the gastrointestinal tract. Pharmateca, 2012, No. 13: S. 9-14. / Abdurakhmanov D.T. Irondeficient anemia in disease of the gastrointestinal tract. Farmateka, 2012, 13: 9-14.

3. Breymann C, Honegger C, Holzgreve W, Surbek D. Diagnosis and treatment of iron-deficiency anaemia during pregnancy and postpartum. Arch. Gynecol. Obstet.. 2010, 282(5): 577-580

4. Breymann C, Milman N. Mezzacasa A, Bernard R, Dudenhausen J. Ferric carboxymaltose vs. oral iron in the treatment of pregnant women with iron deficiency anemia: an international, open-label, randomized controlled trial (FER-ASAP). J Perinat Med. 2016 Jun 8. pii: /j/jpme.ahead-of- print/jpm-2016-0050/ jpm-20160050.xml. doi: 10.1515/jpm-2016-0050.

5. Diagnostics, prevention and treatment of iron deficiency conditions in pregnant women and postpartum women / E.N. Konovodova [et al.] // Obstetrics and gynecology. - 2012. - No. 4/2. - S. 3-10.

6. Ergalieva Zh.S. Treatment of iron deficiency anemia in children / Zh.S. Ergalieva // Bulletin of SKSPA. - 2013. No. 1. - S. 11-14.

7. Feeding and nutrition of infants and young children. Guidelines for the WHO European Region, with emphasis on the former Soviet countries. WHO RegionalPublications, EuropeanSeries, \#87. WHO 2010, updatedreprint 2013.

8. Holm C., Thomsen L.L., Norgaard A., Markova V., Michaelsen K.F., LanghoffRoos J. Iron concentration in breast milk normalized within one week of a singledose infusion of iron isomaltoside in randomized controlled trial ActaPaediatrica, International Journal of Paediatric. 2017. 106 (2): 256260.

9. Iron deficiency anemia: diagnosis. Treatment approaches, liposomal iron (Sideral forte), treatment features. Toolkit. Moscow, 2015, 24 pp. / Irondeficient anemia: diagnostics. Approaches to therapy, lyposomal iron (Sideral Forte), peculiarities of therapy. MethodicalGuidance. Moscow, 2015, $24 \mathrm{p}$.

10. Orziev Z.M. Sulaimonova G.T. Analysis of modern ideas on the formation of critical periods in the occurrence of iron deficiency anemias and their regional features / Therapeutic Bulletin of Uzbekistan. - 2020. - No. 2. - 150-155.

11. UNICEF, United Nations University, WHO. Iron deficiency anemia: assessment, prevention and control. A 
The American Journal of Medical Sciences and Pharmaceutical Research

(ISSN - 2689-1026)

Published: April 30, 2021 | Pages: 165-170

IMPACT FACTOR

2021: 5.64

Doi: https://doi.org/10.37547/TAJMSPR/Volume03Issue04-23

OCLC - 1121105510

guide for programme managers.

Geneva: World Health Organization;

2018 (WHO/NHD/01.3). - 114

p.Availableat: http:

//www.who.int/nutrition/publications/

micronutrients/anaemia_iron_deficien

cyl 